J-Kesmas

Jurnal Kesehatan Masyarakat

\title{
STUDI TENTANG MOTIVASI KUNJUNGAN IBU HAMIL KE POSYANDU DESA BATUPANGA DAALA KEC. LUYO KABUPATEN POLEWALI MANDAR
}

\author{
Rina Sam Sam ${ }^{1}$, Yuliani Soerachmad ${ }^{2}$ \\ Program Studi Kesehatan Masyarakat \\ Fakultas Kesehatan Masyarakat Universitas Al Asyariah Mandar \\ Rinasamsam438@Yahoo.com
}

\begin{abstract}
ABSTRAK
Kunjungan ke Posyandu bagi ibu hamil sangat diperlukan mengingat pemeriksaan dan pemberian tablet Fe juga yang dilaksanakan di Posyandu oleh bidan. Banyak kendala yang dihadapi petugas untuk meningkatkan kunjungan ke Posyandu antara lain, pengetahuan ibu, jarak Posyandu yang relative jauh, persepsi masyarakat/ibu tentang Posyandu itu sendiri. Masyarakat masih perlu dibina dan di ajak utuk selalu berkunjung ke Posyandu, agar kesehatan bayi, balita dan ibu hamil lebih terjaga sehingga dapat meningkatkan derajat kesehatan masyarakat lebih terjamin untuk generasi berikutnya. Jenis penelitian yang digunakan adalah kualitatif dan subjek penelitiannya adalah informan biasa sebanyak tujuh orang, informan kunci sebanyak dua orang penentuan sampel dipilih secara purposive sampling. Hasil penelitian dari 9 informan menunjukkan bahwa kunjungan ibu hamil ke Posyandu Desa Batupanga Daala, sebagian besar keluarga mendukung untuk melakukan pemeriksaan kehamilan namun ibu hamil yang bermasa bodoh dan kurang bersosialisasi. Selain itu ada juga ibu hamil yang merasa nyaman melakukan pemeriksaan di dukun. Hal ini disebabkan petugas kesehatan kadang-kadang tidak hadir akibat akses jalan yang sulit dijangkau dan fasilitas yang ada di Posyandu memiliki fasilitas yang lengkap kecuali di Posyandu Salujerre. Disimpulkan bahwa keluarga mendukung untuk melakukan pemeriksaan kehamilan. Dan kehadiran petugas kesehatan yang kadang-kadang tidak hadir di karenakan akses jalan yang tidak terjangkau, walaupun fasilitas di Posyandu sebagian besar lengkap. Disarankan kepada ibu hamil rutin dalam memeriksakan kandungannya agar setiap masalah kehamilan yang dialalmi terdeteksi secara cepat oleh petugas kesehatan serta sering mensosialisasikan fungsi program pelayanan Antenatal Care yang ada dan melakukan pendekatan terhadap keluarga yang masih sulit melakukan kunjungan ANC.
\end{abstract}

Kata Kunci : Ibu hamil, posyandu

\section{PENDAHULUAN}

Salah satu Upaya Kesehatan

Berbasis Masyarakat (UKBM) yang turut mendukung pelaksanaan program

kesehatan di masyarakat adalah pos pelayanan terpadu (Posyandu) yang di 
J-Kesmas

Jurnal Kesehatan Masyarakat

laksanakan oleh para kader yang berasal dari masyarakat dengan pembinaan dari tenaga kesehatan di Puskesmas. Dalam perkembangannya ternyata Posyandu mendapat tanggapan positif dari masyarakat. Posyandu merupakan langkah yang cukup strategis dalam dalam rangka pengembangan kualitas sumber daya manusia bangsa Indonesia agar dapat membantu dan menolong dirinya sendiri, sehingga perlu ditingkatkan penimbangannya. Posyandu merupakan salah satu upaya pelayanan kesehatan yang di kelola oleh masyarakat dengan dukungan teknis petugas Puskesmas. Posyandu bertujuan untuk memberdayakan dalam memperoleh pelayanan kesehatan dasar utamanya untuk mempercepat angka kematian ibu dan bayi. ${ }^{\mathrm{i}}$

AKI yang didefenisikan sebagai banyaknya kematian perempuan pada saat hamil atau bersalin per 100.000 kelahiran hidup yang disebabkan oleh kehamilan atau pengelolaannya, kecuali yang disebabkan oleh kecelakaan. Pengelolaannya kecuali yang disebabkan oleh kecelakaan yang merefleksikan derajat kesehatan di suatu daerah, yang mencakup tingkat kesadaran perilaku hidup sehat, status gizi dan kesehatan Ibu, kondisi kesehatan lingkungan serta tingkat pelayanan kesehatan terutama bagi ibu hamil, ibu melahirkan dan ibu pada masa nifas. Kesehatan Ibu hamil/bersalin dan AKI memiliki korelasi erat dengan kesehatan bayi dan AKB. Faktor kesehatan ibu saat ia hamil dan bersalin berkontribusi terhadap kondisi kesehatan bayi yang dikandung serta resioko bayi yang dilahirkan dengan lahir mati (still birth) atau yang mengalami kematian neonatal dini (umur 0-6 hari). ${ }^{i i}$

Di Indonesia, pemberian tablet besi kepada ibu hamil sudah di lakukan sejak tahun 1975 dengan melibatkan lintas sector dan lintas program seperti melalui mengintegrasian ke dalam pelayanan Antenatal Care (ANC) oleh bidan terhadap ibu hamil. Pelayanan ini hasilnya belum menggembirakan. Menurut hasil Survey Demografi dan Kesehatan Indonesia (SDKI) tahun 20022003 di provensi Sumatera Utara dilaporkan hanya 2,1\% ibu hamil yang minum tablet besi dengan jumlah hari 60 89 dan sekitar 34,4\% ibu hamil tidak pernah minum tablet besi. Pelayanan ini secara rutin telah dilaksanankan oleh Puskesmas, Puskesmas Pembantu, 
J-Kesmas

Jurnal Kesehatan Masyarakat

Rumah Sakit Umum (RSU), dan klinikklinik swasta, yaitu dengan cara memberikan tablet tambah darah yang berisi $60 \mathrm{mg}$ ferro dan $0,25 \mathrm{mg}$ asam folat kepada setiap ibu hamil minimal 90 tablet selama hamil. ${ }^{\text {ii }}$

Kunjungan ke Posyandu bagi ibu hamil sangat di perlukan mengingat pemeriksaan dan pemberian tablet Fe juga di laksanakan di Posyandu yang di laksanakan di posyandu oleh bidan. Banyak kendala yang dihadapi petugas untuk meningkatkan kunjungan ke Posyandu antara lain, pengetahuan ibu, jarak Posyandu yang relative jauh, persepsi masyarakat/ibu tentang Posyandu itu sendiri. Masyarakat masih perlu dibina dan di ajak utuk selalu berkunjung ke Posyandu,agar kesehatan bayi, balita dan ibu hamil lebih terjaga sehingga dapat meningkatkan derajat kesehatan masyarakat lebih terjamin untuk generasi berikutnya.

Berdasarkan observasi di lokasi, ada beberapa kasus tentang Ibu hamil yang terjadi di masyarakat yang enggan untuk mengontrol ataupun memeriksakan kehamilannya ke bidan, Posyandu, maupun Puskesmas. Hal itu terjadi dikarenakan Ibu hamil merasa malu untuk memeriksakan diri dan kehamilannya, sebab kehamilannya terjadi akibat suatu hubungan diluar nikah, yang kemudian menikah pada usia kandungan 3-5 bulan. Jadi si ibu enggan memeriksakan kandungannya karena merasa baru saja menikah, jadi takut akan anggapan anggapan negatif dari orang - orang sekitarnya. Hal ini tentu sangat tidak baik bagi si Ibu tersebut, sebab seharusnya si Ibu hamil harus lebih mengutamakan kondisi kesehatan kehamilannya dari sekedar perasaan tidak enak ataupun malu yang terus menyelimutinya. Dalam situasi seperti ini tentu peran serta dan dukungan dari keluarga sangat dibutuhkan untuk memberikan support maupun pengertian tentang pentingnya akan kesehatan si ibu dan janin yang di kandungnya.

\section{BAHAN DAN METODE}

Jenis penelitian yang digunakan adalah kualitatif dan subjek penelitiannya adalah informan biasa sebanyak tujuh orang, informan kunci sebanyak dua orang penentuan sampel dipilih secara purposive sampling yaitu sampel diambil bukan tergantung pada populasi melainkan disesuaikan dengan tujuan penelitian. 
J-Kesmas

Jurnal Kesehatan Masyarakat

Tekhnik analisa data menggunakan model analisa editing. Peneliti membaca seluruhhasil wawancara sampai habis serta mencari segmen - segmen penuh arti dalam unit unit. Suatu ketika segmen dikenali dan ditinjau interpretur dikembangkang satu rencana pengelompokan.

Kemudian member kode - kode sesuai untuk memilih jenis dan mengorganisasikan data, kemudian mencari struktur dan pola - pola yang menghubungkan kategori - kategori pokok.

\section{HASIL}

\section{Gambaran Umum Lokasi Penelitian}

Desa Batupanga Daala adalah salah satu Desa yang ada di Kecamatan Luyo dengan luas wilayah $25,74 \mathrm{~km}^{2}$. Desa Batupanga Daala terdiri 4 dusun yaitu Dusun Pallembongan, Dusun Batupanga, Dusun Talepo, Dusun Siratuang dengan jarak ibu kota Kecamatan Luyo $\pm 6 \mathrm{~km}$ yang termasuk Wilayah kerja Puskesmas Batupanga.

\section{Dukungan Keluarga}

Berdasarkan hasil wawancara mendalam (indept interview) dengan informan biasa, sifatnya lebih spesifik yang menyatakan bahwa keluarga mendukung untuk tetap melakukan pemeriksaan kehamilan demi mencegah hal - hal yang tidak diinginkan sedangkan keluarga yang tidak mendukung disebabkan faktor kesibukan atau lupa.

ibu hamil yang mendapat informasi mengenai pentingnya pemeriksaan kehamilan yaitu dari keluarga yang berdasarkan pengalaman pemeriksaan kehamilan dan ibu hamil yang tidak mendapatkan informasi mengenai pentingnya pemeriksaan kehamilan karena disebabkan ibu hamil yang bermasa bodoh serta kurang bersosialisasi dan sebagian besar masih memilih untuk ke dukun, sehingga informasi akan pentingnya pemeriksaan kehamilan tidak diprioritaskan oleh sebagian ibu hamil yang ada di Batupanga.

\section{Kehadiran Petugas Kesehatan}

Berdasarkan hasil wawancara dengan informan frekuensi petugas kesehatan yang kadang - kadang hadir dan dan kadang - kadang tidak karena disebabkan akses jalan yang kadang tak bisa di jangkau khususnya dimusim 
$\mathrm{J}$-Kesmas

Jurnal Kesehatan Masyarakat

hujan serta terkadang pertemuan rapat petugas kesehatan bertepatan dengan Posyandu.

Ibu hamil mendapatkan informasi mengenai manfaat pentingnya pemeriksaan kehamilan tetapi masih ada sebagian ibu hamil yang kurang memahami apa yang di tuturkan oleh petugas kesehatan melakukan penyuluhan mengenai manfaat pemeriksaan kehamilan serta masih ada sama sekali ibu hamil yang tidak mendapatkan informasi dengan lengkap dan jelas tentang manfaat pemeriksaan kehamilan terutama jika petugas kesehatan dalam keadaan sibuk. Petugas kesehatan di Desa Batupanga Daala masih tebatas dan kader Posyandu juga kurang aktif.

\section{Fasilitas ( Sarana dan Prasarana )}

Berdasarkan hasil penelitian secara mendalam dengan informan, bahwa sebagian besar Posyandu di Desa Batupanga Daala Kec. Luyo Kabupaten Polewali Mandar sudah memiliki fasilitas lengkap dan Posyandu yang fasilitasnya belum lengkap juga sudah dalam keadaan kelengkapan fasilitas.

\section{PEMBAHASAN}

\section{Dukungan Keluarga}

Dukungan keluarga khususnya suami memiliki peranan yang sangat penting secara psikologis maupun mental. Sebagian besar informan menyatakan mendapatkan dukungan dari keluarga, bentuk dukungan yang diberikan misalnya menganjurkan untuk melakukan pemeriksaan kehamilan agar dapat mengetahui masalah - masalah yang terjadi pada kehamilan, mengetahui perkembangan janin dalam kandungan serta kesehatan tetap terjaga dengan atur - aturan yang di anjurkan oleh ibu bidan seperti makan-makanan yang bergizi yaitu makan buah segar, sayuran, daging, ikan, dan kacang - kacangan, kemudian di anjurkan banyak istirahat serta mengurangi minum kopi selama hamil karena dapat mengurangi penyerapan makanan khususnya zat besi dalam tubuhdan dianjurkan minum tablet besi folat untuk mencegah anemia selama hamil, namun ada juga ibu hamil mendapat dukungan tapi tidak pergi melakukan pemeriksaan disebabkan faktor malu dengan tanggapan orang mengenai 
J-Kesmas

Jurnal Kesehatan Masyarakat

kehamilannya karena suami pergi merantau kemudian disebabkan faktor rumah ibu hamil yang jauh dari perkampungan yang menyebabkan ibu hamil malas pergi memeriksa dan suami juga tidak ada inisiatif untuk mengantar karena lebih memilih ke kebun dan disebabkan masih adanya ibu hamil yang gensi untuk melakukan pemeriksaan karena umur yang masih belia walaupun sudah menikah, juga disebabkan masih ada ibu hamil yang lebih memilih ke dukun beranak.

Seedangkan yang tidak mendapat dukungan disebabkan faktor kesibukan seperti lebih memilih mengurus usaha dan ke kebun kemudian ada juga faktor ketidak cocokan ibu hamil dan keluarga serta suami yang pergi merantau, dan ada juga ibu hamil tidak mendapat dukungan dari keluarga tapi melakukan pemeriksaan dengan inisiatif sendiri demi kesehatan diri sendiri dan janin yang di kandung.

Dukungan sosial yang paling diperlukan bagi seorang ibu dalam menghadapi periode perinatal adalah keluarga. Ibu hamil selama sekitar 9 bulan mengalami dan merasakan fase fase pertumbuhan janin yang membutuhkan dorongan mental dari lingkungan. Dalam hal ini fungsi dukungan keluarga bagi ibu hamil yakni akan mendatangkan rasa senang, rasa aman, rasa puas, dan rasa nyaman yang akan membuat ibeu hamil akan merasa mendapat dukungan secara emosional yang akan mempengaruhi kesehatan jiwanya (Mahmunah, 2010). Pada masa kehamilan, peran suami sangat penting untuk memotivasi istri terus menjaga kesehatan dengan mengomsumsi makanan yang bergizi, istirahat yang cukup, terus bersabar serta mendampinginya setiap memeriksakan kehamilan (Anshor dan Abdullah Ghalib, 2010 ). Manuaba dkk (2003), menyatakan bahwa ibu hamil yang kekurangan dukungan psikologis dan sosial budaya dari keluarga yang paling dekat, khususnya suami, akan cenderung mengalami strees pada kehamilan. Mahmunah (2010) juga menambahkan bahwa jika seluruh keluarga mengharapkan kehamilan, mendukung bahkan memperlihatkan dukungannya dalam berbagai hal, maka ibu hamil akan merasa lebih percaya diri, lebih bahagia dan siap 
J-Kesmas

Jurnal Kesehatan Masyarakat

menjalani kehamilan, persalinan dan masa nifas.

Penelitian ini sejalan dengan penelitian yang dilakukan Ira dkk, dengan judul pemanfaatan Antenatal Care (ANC) oleh ibu hamil pada masyrakat Desa Makupa Kecamatan Lambandia Kabupaten Kolaka Timur tahun 2015. Adapun hasil penelitian yang diperoleh yaitu berdasarkan hasil wawancara diperoleh informan bahwa, (1) Anjuran untuk memeriksakan kehamilan berasal dari dukungan suami, keluarga dan kemauan sendiri. (2) Pemeriksaan kehamilan biasa ditemani dengan suami dan keluarga tetapi ada juga informan yang melakukan pemeriksaan kehamilan tanpa ditemani keluarganya.

Pemeriksaan kehamilan selalu diingatkan oleh keluarganya. iv

\section{Kehadiran Petugas Kesehatan}

Berdasarkan hasil penelitian yang dilakukan di Desa Batupanga Daala Kec. Luyo Kabupaten Polewali Mandar tentang kehadiran petugas kesehatan di Posyandu, menunjukkan bahwa frekuensi kehadiran petugas kadang - kadang hadir dan kadang - kadang tidak disebabkan karena akses jalan terkadang tidak bisa di jangkau kendaraan roda empat maupun roda dua dan kadang - kadang petugas mengikuti pertemuan yang bertepatan dengan Posyandu.

Kemudian adapun informasi yang di dapatkan oleh ibu hamil mengenai pemanfaatan pemeriksaan kehamilan seperti makan makanan yang bergizi, dianjurkan banyak istirahat dan yang mendapat informasi pemeriksaan kehamilan tapi tidak menjalankan perintah yang dianjurkan oleh bidan seperti kurang makan buah - buahan karena jarang kepasar serta pasar jauh dari Desa Batupanga Daala, sedangkan yang tidak mendapat informasi karena ibu hamil tidak pergi periksa serta ibu hamil yang kurang bersosialisasi.

Kehadiran petugas kesehatan dengan masyarakat merupakan titik tolak keberhasilan atau kegagalan upaya peningkatan kesadaran masyarakat akan hidup sehat. Petugas kesehatan berperan sebagai pendidik kesehatan, sumber informasi dan motivator, keberhasilan upaya peningkatan derajat kesehatan 
J-Kesmas

Jurnal Kesehatan Masyarakat

masyarakat. Pada setiap posyandu yang berjalan lancer dan teratur selalu ada tokoh motor penggerak Posyandu secara langsung maupun tidak langsung. Dukungan Puskesmas dan bidan desa motivasi yang penting bagi kader dan masyarakat pelayanan kesehatan berupa pengobatan sederhana, ada pemberian makanan tambahan yang teratur dan menarik, insentif kader dan dukungan dari tokoh masyarakat ( Sumarno, 2006).

Hal ini sejalan dengan penelitian yang dilakuakan oleh Widiastuti bahwa kehadiran petugas menjadi salah satu daya tarik bagi ibu balita untuk membawa anaknya ke Posyandu.

\section{Fasilitas ( Saranan dan Prasarana )}

Berdasarkan hasil penelitian terhadap informan mengenai fasilitas mennyatakan bahwa terhadap fasilitas yang ada di Posyandu termasuk lengkap seperti alat pemeriksaan kehamilan, alat pengukur tinggi pundus, penimbangan BB, LILA, dopler, brangkar dan pengukur tinggi badan, kemudian ada juga informan yang menyatakan bahwa fasilitas di
Posyandu tidak lengkap seperti tidak adanya brangkar sehingga menyebabkan ibu hamil kadang malas memeriksakan kehamilan, sedangkan ada juga ibu hamil yang tidak tahu mengenai kelengkapan fasilitas di Posyandu karena tidak pernah melakukan pemeriksaan.

Hasil penelitian ini sejalan dengan teori yang menyatakan bahwa fasilitas ialah segala wahana dan prasarana yang bisa menunjang kepada kesehatan kita, baik kesehatan jasmani maupun kesehatan rohani.

\section{KESIMPULAN}

1. Sebagian keluarga mendukung untuk melakukan pemeriksaan kehamilan di setiap Posyandu Desa Batupanga Daala Kec. Luyo Kabupaten Polewali Mandar.

2. Kehadiran petugas kesehatan di Posyandu Desa Batupanga Daala Kec. Luyo Kabupaten Polewali Mandar kadang - kadang tidak hadir dikarenakan akses jalan yang kadang tidak terjangkau serta jadwal pertemuan petugas kesehatan bertepatan dengan Posyandu. 
Vol. 3, No. 2, Nopember 2017

$\mathrm{J}$-Kesmas

Jurnal Kesehatan Masyarakat

3. Fasilitas di Posyandu Desa Batupanga Daala Kec. Luyo Kabupaten Polewali Mandar sebagian besar sudah memiliki fasilitas lengkap.

\section{SARAN}

1. Pemerintah lebih memaksimalkan program pelayanan kesehatan ibu dan anak di Desa Batupanga Daala Kec. Luyo Kabupaten Polewali Mandar.

2. Sebaiknya ibu hamil rutin dalam memeriksakan kandungannya agar setiap masalah kehamilan yang dialami terdeteksi secara cepat oleh petugas kesehatan.

3. Membuat kesepakatan dengan kader dan masyarakat tentang jadwal pelaksanaan Posyandu yang diadakan setiap bulannya.

4. Memberikan pengumuman sehari sebelum pelaksanaan Posyandu dengan cara memberikan undangan.

5. Melakukan pendekatan dengan tokoh masyarakat untuk resosialisasikan kegiatan-kegiatan yang ada di Posyandu.

6. Mempelajari secara mendalam serta mencari solusi terhadap alasan masyarakat yang kurang memanfaatkan sarana pelayanan
p-ISSN: 2442-8884 / e-ISSN: 2541-4542

kesehatan dan meningkatkan kualitas pelayanan kesehatan, serta lebih sering mensosialisasikan fungsi dari setiap program pelayanan Antenatal Care yang ada dan melakukan pendekatan terhadap keluarga keluarga yang masih sulit melakukan kunjungan kepelayanan ANC.

Perlu dilakukan penelitian lebih lanjut dengan menggunakan rancangan metode analisis lain agar didapat hasil yang menjelaskan lebih menyeluruh tentang studi motivasi terhadap kunjungan ibu hamil.

\section{DAFTAR PUSTAKA}

Departemen kesehatan RI. 2012. Peningakatan Perang Serta Masyarakat Dalam Kegiatan Posyandu. Jakarta.

Profil Kesehatan Provinsi Sulawesi Barat. 2014.http://www.depkes.go.id/resourc es/download/profil/PROFIL_KES_PR OVINSI_2014/30_Sulawesi_Barat_2

014.pdf

Tungkup, Juliana. L.. 2008. FaktorFaktor yang Mempengaruhi Ibu Hamil Melakukan Kunjungan ANC di Rumah Sakit Kota Medan. 
Vol. 3, No. 2, Nopember 2017

p-ISSN: 2442-8884 / e-ISSN: 2541-4542

J-Kesmas

Jurnal Kesehatan Masyarakat

http://repository.usu.ac.id/jspuix 1/ha $\underline{\text { ndle/123456789/16572 }}$

Elide Hairunida. 2012. Faktor - faktor yang berhubungan dengan perilaku kunjungan ke Posyandu pada ibu balita di wilayah kerja puskesmas pancoran mas kota depok. related:lib.ui.ac.id/file?file=digital/20 319826-S-PDF

Elida\%20Hairunida\%20BR\%20Purb a.pdf

Kementrian Kesehatan RI. 2011. Pedoman umum pengelolaan Posyandu. Jakarta.

Dewi. 2011. Asuhan Kehamilan Untuk Kebidanan.Jakarta: Salemba Medika. Www:gusedy.blogspot.com/2007/06/ Analisa Pelayanan KIA Jawa Tengah.html.

Firmansyah, F. Hubungan Pengetahuan dan Sikap Ibu Hamil Terhadap Perilaku Kunjungan Pemeriksaan Kehamilan di Puskesmas Rawat Inap Kedaton Bandar Lampung. 2008.Jur Kedokteran 2.rar - RAR archive, unpacked size 6.993 .064 bytes .

Yani. 2006. Antenatal Care Focused. Yogyakarta: Nuha Offset.
Notoadmojo. 2010. Pengaruh Motivasi Pemeriksaan Kehamilan ANC. www// http. Litbang. Depkes. Kesrepro info.go.id

Mufdillah. 2009. Motivasi terhadap pelayanan $A N C$.

http://digilib.unimus.ac.id/files/disk1/ 106/jtptunimus-gdl-retnowatig-52943-bab2.pdf

Ira dkk. 2015. Pemanfaatan Antenatal Care (ANC) oleh ibu hamil pada masyarakat Desa Makupa Kecamatan Labandia Kabupaten Kolaka Timur . 